\title{
Assessment of Mutual Probabilistic Influence of Volatility of Official Price for Precious Metals on the Market Value of the Bi-Currency Basket
}

\author{
Bagautdinova N. ${ }^{a}$ \\ Tsaregorodtsev E. ${ }^{b}$ \\ Kulalayeva I.c \\ Arzhantseva N.d
}

a bcd Kazan Federal University, Kazan, 420008, Russia

\section{Doi:10.5901/mjss.2014.v5n12p33}

Abstract.

The given article describes the degree of mutual probabilistic influence of volatility of official price for precious metals (gold, silver, platinum, palladium) on the market value of bi-currency basket the identification of which allows to make decisions about the placement of money in cash in the period of world financial instability for the purpose of increasing the financial safety or as an option for receiving profit the long-run period. The regression model is used as an instrument of mathematic economic modeling.

Keywords: volatility, market value of bi-currency basket, official price for gold, silver, platinum, palladium, regression equation

\section{Introduction}

At present, in the conditions of sharp volatility of the exchange rate and instability of international economic and the monetary and financial relations causing negative social and economic consequences, i.e. losses of some participants and pay-offs of the others, it is interesting to define and analyze the degree of mutual probabilistic influence of volatility of the official price for precious metals of the Central Bank of the Russian Federation (gold, silver, platinum, palladium) on the market value of bi-currency basket (BB) [1].

\section{Methodology}

In this case, relying on the analysis of socio-economic essence of the studied phenomenon and the results of observations, we will choose a type of a regression equation [2], considering the dependence of an average value of any random variable $Y$ on some other one - $X$, we will apply the equation of linear pair regression (ELPR) [2]:

$$
\hat{y}=a+b x
$$

For the assessment of parameters $a$ and $b$ by the least square method (LS method) it is necessary to solve the system of normal equations of the following kind:

$$
\left\{\begin{array}{l}
n a+b \sum x=\sum y \\
a \sum x+b \sum x^{2}=\sum y x
\end{array}\right.
$$

The regression coefficient $b$ shows by how many units in average the resultant variable $Y$ will change if the factor variable $X$ increases by one unit.

For the assessment of the ratio of linear connection between variables the linear coefficient of pair correlation is used:

$$
r_{x y}=b \frac{\sigma_{x}}{\sigma_{y}}=\frac{\overline{x \cdot y}-\bar{x} \cdot \bar{y}}{\sigma_{x} \cdot \sigma_{y}}
$$

with $\sigma_{x}=\sqrt{D_{x}}=\sqrt{\overline{x^{2}}-\bar{x}^{2}}$ - standard deviation $X ; \sigma_{y}=\sqrt{D_{y}}=\sqrt{\bar{y}^{2}-\bar{y}^{2}}$ - standard deviation $Y$.

For the assessment of quality of the regression equation the determination coefficient is used. It describes the part of dispersion interpreted by regression in the dispersion of the performance index (squared correlation coefficient): 


\section{$R^{2}=r_{x y}^{2}$}

The determination coefficient shows, what part of a variation (change) of a productive variable $Y$ is described by the variation of factor $X$. The closer $R^{2}$ is to the unit, the more qualitative the regression model is.

The assessment of statistical importance of the regression equation in general is carried out by means of Fischer's variance ratio. The hypothesis of $H_{0}$ of statistical insignificance of the regression equation is checked. For this purpose the actual value of the ratio is calculated using the formula:

$$
F_{\text {fact. }}=\frac{R^{2}}{1-R^{2}} \cdot(n-2) \text {, }
$$

With $n$ - number of the units of population.

Ftable is determined by the table of critical points of distribution of Fischer-Snedekor - the biggest possible value of the criterion which could be formed under the influence of random factors at these degrees of freedom and a significance level $\alpha$. Significance level $\alpha$ is the probability to reject the correct hypothesis provided that it is correct.

For ELPR with the significance level $\alpha=0,05$ it is necessary to find the value $F(0,05 ; 1 ; n-2)$ in the table of values. If $F_{\text {table }}<F_{\text {fact }}$, the hypothesis of $H_{0}$ of random nature of the estimated characteristics deviates and admits their statistical importance and reliability.

We will carry out the relevant statistical analysis on the basis of the equation of linear pair regression with the usage of daily values of the official price for precious metals (gold, silver, platinum, palladium) of the Central Bank of the Russian Federation (rub/gram) and of the cost of the bi-currency basket of the Central Bank of the Russian Federation, from 02.07.2008 to 30.04.2012 inclusive (4264 observations) [3].

On the basis of the conducted research the following results were obtained:

Influence of the official price for gold on the market value of $B B$

As a result of the conducted research the following ELPR is received:

$Y=29,0077+0,0056 \cdot X$,

with $x$ - official price for gold, $Y$ - market value of BB.

The significance and reliability of the used ELPR and the indicator of close ties are confirmed by the values $F_{\text {fact }}=171,20>F_{\text {table }}=3,86$. That is the growth of the official price for gold by one rouble will increase the cost of a bicurrency basket by $0,01 \%$ on average.

The influence of the official price for silver on a bi-currency basket.

As a result of the conducted research the following ELPR is received:

$Y=33,4091+0,0850 \cdot X$,

with $x$ - official price for silver, $Y$ - market value of BB.

The significance and reliability of the used ELPR and the the indicator of close ties are confirmed by the values

$F_{\text {fact }}=23,87<F_{\text {table }}=3,86$. So the growth of the official price for silver by one rouble will increase the cost of a bi-currency basket by $0,09 \%$ on average - this is the highest value of the influence of the precious metal for the period researched.

Though the results of the conducted research for 2011 showed lack of influence of the official price for silver of the Central Bank of the Russian Federation on the market value of the bi-currency basket of the Central Bank of the Russian Federation, ELPR looks like:

$Y=35,5411+0,0290 \cdot X$,

with $x$ - official price for silver, $Y$ - market value of BB .

Values $F_{\text {fact }}=2,01<F_{\text {table }}=3,88$ reject the importance and reliability of the used equation of regression and the indicator of close ties.

The influence of the official price for platinum on a bi-currency basket.

As a result of the conducted research the following ELPR is received:

$Y=32,5751-0,0017 \cdot X$,

with $x$ - official price for platinum, $Y$ - market value of BB.

The significance and reliability of the used ELPR and the the indicator of close ties are confirmed by the values $F_{\text {fact }}=21,58<F_{\text {table }}=3,86$. So the growth of the official price for platinum by one rouble will lower the cost of a bicurrency basket by $0,002 \%$ on average.

The influence of the official price for palladium on a bi-currency basket.

As a result of the conducted research the following ELPR is received:

$Y=34,8082-0,0001 \cdot X$, 
with $x$ - official price for palladium, $Y$ - market value of BB.

Values $F_{\text {fact }}=0,05<F_{\text {table }}=3,86$ reject the importance and reliability of the used equation of regression and the indicator of close ties.

So the growth of the official price for palladium will not influence the cost of a bi-currency basket.

Though the results of the conducted research for 2011, on the contrary, showed influence of the official price for palladium of the Central Bank of the Russian Federation on the market value of BB of the Central Bank of the Russian Federation, ELPR:

$$
Y=42,6465-0,0117 \cdot X \text {, }
$$

where $x$ - official price for palladium, $Y$ - market value of BB.

So the growth of the official price for palladium by one ruble will lower the cost of a bi-currency basket by $0,01 \%$ on average.

The significance and reliability of the used ELPR and the indicator of close ties are confirmed by the values $F_{\text {fact }}=73,82<F_{\text {table }}=3,88$

\section{Results}

The conducted research brought to the following conclusions. First, the demand for platinum and palladium is formed in three directions: in production of jewelry, as the catalyst in purification of crude oil, for the use in automobile catalytic converters. Their price generally depends on the industrial demand of the world auto industry. Weakening of the main world economies led to the sales in the market of palladium and the investors demand for these metals is constantly falling because of rather low liquidity and their limited application in the jeweler industry and possible risks on the supplyside.

The investment demand continues to experience decrease in platinum and palladium according to the decreasing dynamics of physical investments of ETF platinum and palladium. At the same time expectations of the participants of the market concerning these metals resumed their decrease - the consensus of Bloomberg decreased in platinum from $\$ 1850$ to $\$ 1811$ for a year, and in palladium — from $\$ 835$ to $\$ 805$ for ounce.

In this case low demand for platinum and palladium is caused by their popularity as industrial metals, not the investment ones. The available demand is generally created by the demand of small business for the production of jewelry.

The general demand for palladium is actual, physical, with the account to the dynamics which isn't worse than for gold.

Secondly, sharp weakening of the physical investment demand for silver is a negative factor, whereas for gold the growth of physical investments in ETF has already slowed down. Speculative activity for silver was the cause for an agiotage rise in prices in the last two years three times, because of covering of short positions At the moment it also remains to the lowest. The volume of open contracts for silver after a small splash at the beginning of November returned to the minimum values, thus, speculators set themselves up to continue the consolidation of prices for silver. Risks of slowing down of industrial demand testify that the revision of expectations down is not going to stop.

The seasonal factor of demand for silver is under the influence of growth of industrial demand. About $40 \%$ of silver are used in production of solar batteries, in water-purification systems, mobile phones, plasma TVsets and devices of radio-frequency identification.

As it is expected, the industrial demand for silver will annually grow by $10 \%$. The demand for silver for production of photos will remain, but at a low level; the demand for silver jewelry will continue slow growth, despite the rise in prices for silver.

The world demand for silver will also support the investment sector which offers great opportunities for investing in silver. At present in the world there is a large number of investment funds which offer investors to invest their money in silver. Therefore at the beginning of the year 2012 the price for silver has to get considerable support. Now silver is bargained for $\$ 30$ per one ounce.

Trade restrictions, speculations on the currency markets, changes in price for raw materials (oil and gas), inflationary expectations of economic subjects, price proportions within the country and other factors have a great impact on the exchange rates, the cost of the bi-currency basket and the price of precious metals, but the behavior of the people tells that:

1. The currency markets quickly react to any economic or political diversification, to the volatility of exchange rates. 
2. Mistrust to cross rates is traced on the basis of disruptions of stock markets.

3. Only the price for gold exhibited positive dynamics throughout many centuries.

4. The main objective of purchase is the increase of financial safety.

5. Gold is a lead indicator of inflation and a reliable object of investment of capital in the periods of economic and financial instability as it is effective in the long-term prospect and shows high liquidity.

6. Investments in gold at the growth of the world prices for precious metals can bring in an additional income.

The conclusions were made on the basis of the analysis of the dynamics of prices for gold, platinum and palladium in 2013 - beginning of 2014. (fig. 1, 2, 3).

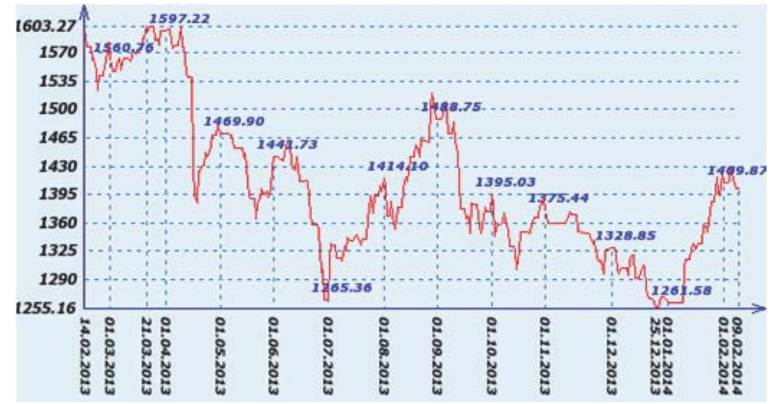

Fig.1. The diagram of the change in price for gold in 2013 - beginning of 2014.

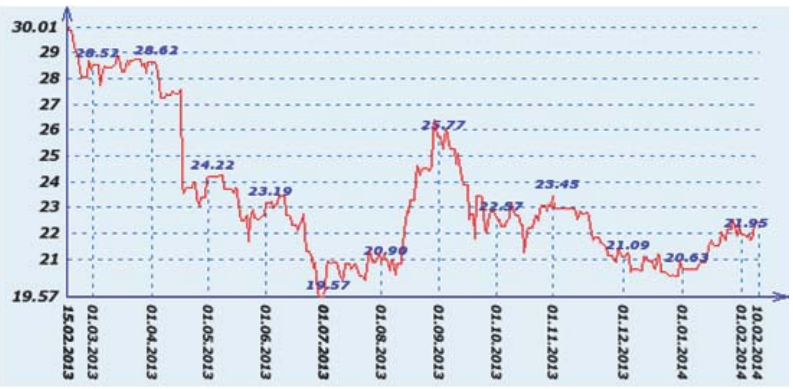

Fig.2. The diagram of the change in price for platinum in 2013 - beginning of 2014.

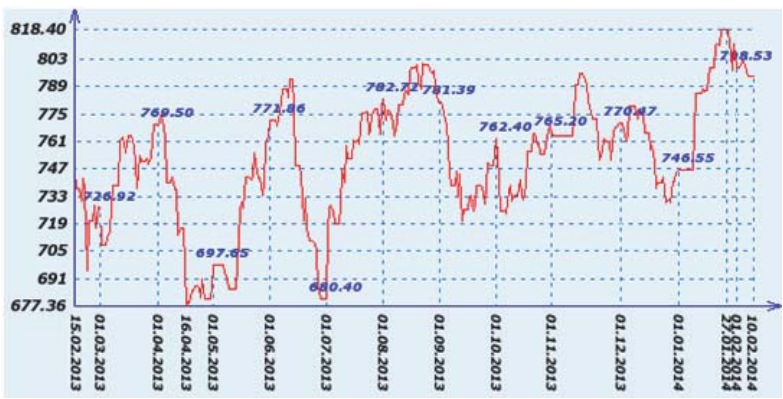

Fig.3. The diagram of the change in price for palladium in 2013 - beginning of 2014

The bank establishes the quotations of purchase and sale of precious metals in the impersonal form with the account to the current official prices for precious metals established by the Bank of Russia, the situation on domestic market of precious metals, and also the tendencies of fluctuations of current prices on the world market of precious metals.

The volatility of exchange rates formed under the influence of the change in prices for raw materials (oil, gas), 
political and financial changes in countries, purchases and monetization of debts of private and national sectors, policy of low interest rates, growth of budget deficit and debt burden of the states amid the continuing panic, inflation and deflation of the world economy are the fundamental factors of investments in precious metals and growth of the price for gold [4, 13]. Therefore amid the general demand for the yellow metal and a growing agiotage among the population the Central Bank of Russia raised the sell prices of investment coins made from gold and silver since 08.08.2011.

Though as the result of the quotation price adjustment which began at the end of June and lasted almost until the end of July, 2010, the price for gold fell to 1150 dollars/ounce: as the confidence of investors in the recovery of the world economy grew, the funds passed into more risky assets and the assets possessing higher profitability (equity markets, energy markets and industrial metals markets). However in August fears concerning the fragility of economies of the developed countries increased. The world indexes of business activity declined to the mark of 50 points, having caused fears concerning the second wave of recession. These factors allowed the prices for gold to shoot up again. The same occurred in 2011 - the record price of 1828,22 rub /gr. for the yellow metal was recorded 22.09.2011 according to the data of the Central Bank of the Russian Federation.

The investment demand keeps the prices for gold at high levels, regardless of a growing gap between the offer and fundamental sources of demand. While there are fears concerning recession and deflation, and while large Central Banks show readiness to increase their balances at the expense of increase of money supplies, prices for gold will be supported $[10,14]$. Gradual return to normal economic conditions (the main powers will bring order to their financial systems by the reduction of the budget expenditures; economic growth, interest rates and inflation will recover to the pre-crisis levels) will provoke decrease the force of attractiveness of gold $[12,16]$.

Concerning the placement and storage of gold and gold and foreign currency reserves of the Russian Federation for the purpose of its effective and profitable investment with the account to all results of the carried-out and described above analytical and practical research, it is necessary to recommend to the financial authorities of the Russian Federation (the Central Bank of the Russian Federation) to keep the minimum part of gold and foreign currency reserve in currency necessary for providing a common trade turnover, and to store the other part of the reserve in gold, as the asset possessing monetary function and preserving its cost, the asset which confirmed its efficiency in the long-term prospect for the purpose of foreign currency hedging.

\section{Conclusions}

Gradually the equilibrium of the gold market will be reflected on investors. If moderate positive expectations concerning the further destiny of world economy will turn real, it will create certain difficulties for the gold market. In particular, when the world stock markets start moving to normal condition, the interest rates will start to grow and alternative investments to bring more attractive incomes, zero profitability of gold (if we consider the costs for storage) and ambiguous prospects of growth of the capital will cause the loss of interest from investors $[3 ; 5,15]$.

In the conditions of the world financial instability the main investors, who haven't decided which of the factors (the price for oil or existing budget deficit) will manipulate the currency market and strongly affect the exchange rate between the ruble and the US dollar/euro and respectively the cost of the bi-currency basket, while placing cash (investment) should necessarily be guided by the underestimated and industrially focused precious metals as a source of hedging (they show rather high level of protectability from inflation and possess high liquidity) and a stable profitable investment (they are effective in long-term prospect and with a growth of the world prices for precious metals can bring some additional income). Because of the requirement of industry the demand for them at worst may remain stable which will be the guaranteed pawn for the successful monetary credit and exchange rate policy of the Central Bank of the Russian Federation in achievement of financial stability on condition of the modern mechanism of international monetary and financial relations. Thus, the balanced portfolio is the guaranteed source of high income due to predicted industrial demand for four precious metals (Au, Ag, Pt, Pd).

\section{References}

Ceberio J.. A linearregression analysis.Springer-Verlag, 1980.- 452 p.

Gainova R.A., Shaidullin R.N., Safiullin L.N. and Maratkanova E.M. Infrastructural Component in Maintenance of Competitiveness of Region// World Applied Sciences Journal, 27(13), 2013, pp. 97-101.

Frumkin N. Guide to Economic Indicators. - M.E.Sharpe Inc,New York, London, 1990.

Safiullin L.N., Gafurov I.R., Shaidullin R.N., Safiullin N.Z. Socio-economic development of the region and its historical and cultural heritage. Life Science Journal 2014; 11(6s): 400-404. 
Frumkin N. Tracking America's Economy. - M.E.Sharpe Inc, New York, London, 1992.

Grabbe J.O. International Financial Markets. - Prentice Hall, Engl. Cliffs, New Jersey, 1994.

Safiullin M.R., Samigullin I.G. and Safiullin L.N. Model of Management of Competitiveness of a Machine-building Complex// World Applied Sciences Journal, 27(13), 2013, pp. 212-216.

Holden K., Peel D.A., Thompson J.L. Economic forecasting: an introduction. - Cambridge Univ. Press, 1990.

Validova A.F. Inflation targeting in developing countries: perspectives for Russia. Life Science Journal 2014; 11(6s): 494 - 498.

Klopfenstein G., Stein J. Trading Currency Cross Rates. - J. Wiley \& Sons, New York e.a., 1995.

Fakhrutdinova, E., Kolesnikova, J., Yurieva, O., Kamasheva, A. The commercialization of intangible assets in the information society/l World Applied Sciences Journal. Volume 27, Issue 13, 2013, Pages 82-86.

Kramin M.V., Safiullin L.N., Kramin T.V., Timiryasova A.V. Drivers of economic growth and investment attractiveness of Russian regions. Life Science Journal 2014; 11(6s): $526-530$.

Niemira M.P., Zukovski G.F. Trading the Fundamentals (The trader's complete guide to interpreting economic indicators \& monetary policy). - IRWIN, Chicago e.a., 1994.

Rothstein N.H. (ed.) The Handbook of Financial Futures. A Guide for Investors and Professional Financial Managers. -McGraw-Hill Book Company, New York e.a., 1984.

Kirshin I.A. Modeling the long-term trend of accumulation of knowledge. Life Science Journal 2014; 11(6s): 482 - 486.

Van Horn J.C. Financial Market Rates and Flows. - Prentice Hall, Englewood Cliffs, New Jersey, 1994 